\title{
Predictors of employees' job satisfaction through corporate social responsibility (CSR) practices in Malaysian banking company
}

\begin{abstract}
The purpose of this study was to examine the relationship between dimensions of corporate social responsibility (CSR) practices and job satisfaction of employees in one of the banking companies in Malaysia. The study utilised CSR dimensions based on Carroll's (2004) revised pyramid of global CSR and performance model and the elements that developed by Mohd Hasan (2013) based on extensive reviews of global and local CSR best practice standards. A survey method was employed using multistage sampling. Questionnaires were distributed to 353 bank staff (managerial and non-managerial), generating 174 valid responses. The data were then analysed using Pearson-Product Moment Correlation and Multiple Regression tests using the stepwise method through the Statistical Package for the Social Sciences (SPSS) version 22.0. Based on the findings, financial necessity under the economic dimension, compliance with certified international standards under legal dimension, and community driven under philanthropy dimension yielded positive and moderate relationships with job satisfaction. However, environmental stewardship and social reporting categorised within the ethical CSR dimension have a positive but weak correlation with job satisfaction. Multiple regression analysis showed only community driven from the philanthropy dimension and compliance with certified international standards from the legal dimension were the significant predicting factors for job satisfaction in the current context. Conclusion, limitations of the study, implications of the findings, and suggestions for future study are also discussed.
\end{abstract}

Keyword: Banking company; Dimensions of corporate social responsibility; Employees; Job satisfaction 